Article

\title{
What Are the Structural Barriers to Planning for Later Life? A Scoping Review of the Literature
}

\author{
Claire Preston ${ }^{1, *}$, Nick Drydakis ${ }^{2}$, Suzanna Forwood ${ }^{3}$, Suzanne Hughes ${ }^{4}$ and Catherine Meads ${ }^{4}$ \\ ${ }^{1}$ Humanities and Social Sciences, Anglia Ruskin University, Cambridge, CB1 1PT, UK; E-Mail: claire.preston@anglia.ac.uk \\ 2 Economics, Finance and Law, Anglia Ruskin University, Cambridge, CB1 1PT, UK; E-Mail: nick.drydakis@anglia.ac.uk \\ ${ }^{3}$ Psychology and Sport Science, Anglia Ruskin University, Cambridge, CB1 1PT, UK; E-Mail: suzanna.forwood@anglia.ac.uk \\ ${ }^{4}$ Nursing and Midwifery, Anglia Ruskin University, Cambridge, CB1 1PT, UK; E-Mails: suzanne.hughes@anglia.ac.uk (S.H.), \\ catherine.meads@anglia.ac.uk (C.M.)
}

* Corresponding author

Submitted: 13 December 2018 | Accepted: 18 March 2019 | Published: 29 July 2019

\begin{abstract}
The rollback of the welfare state in countries such as the UK, coupled with population ageing, have contributed to a situation in which responsibility for older people's wellbeing is placed more heavily on the individual. This is exemplified in the notion in popular and policy circles that individuals should plan for later life, particularly financially, and a corresponding concern that they are not doing so sufficiently. This scoping review aimed to identify the structural factors which inhibit people from engaging in planning for later life. For the purposes of this review, we characterised planning as the range of activities people deliberately pursue with the aim of achieving desired outcomes in later life. This entails a future, as opposed to shorter-term, goal orientation. In study selection, we focused on planning at mid-life (aged 40 to 60). Systematic and snowball searching identified 2,317 studies, of which 36 were included in the final qualitative synthesis. The review found that limited financial resources were a key barrier to planning. Related factors included: living in rented accommodation, informal caring, and working part-time. A lack of support from employers, industry, regulators and landlords was also found to inhibit planning. The findings suggest that certain sections of society are effectively excluded from planning. This is particularly problematic if popular and policy discourse comes to blame individuals for failing to plan. The review also provides a critical perspective on planning, highlighting a tendency in the literature towards individualistic and productivist interpretations of the concept.
\end{abstract}

\section{Keywords}

ageing; later life; mid-life; older people; planning; retirement; scoping review; structural barriers

\section{Issue}

This article is part of the issue "Old-Age Exclusion”, edited by Wouter De Tavernier (KU Leuven, Belgium) and Marja Aartsen (OsloMet-Oslo Metropolitan University, Norway).

(C) 2019 by the authors; licensee Cogitatio (Lisbon, Portugal). This article is licensed under a Creative Commons Attribution 4.0 International License (CC BY).

\section{Introduction: Background}

This review draws on Street and Desai (2011) to characterise planning as the range of activities people deliberately pursue with the aim of achieving desired outcomes in later life. Planning entails a future goal orientation and typically concerns issues such as finance, housing, and leaving work.
The austerity agenda, coupled with the ageing of the population have helped focus European and UK government policy on two areas related to planning: extending working lives and savings (Chartered Institute of Personnel and Development [CIPD], 2016; Department of Work and Pensions [DWP], 2013, 2017; Eurofound, 2007, 2016; Lifelong Learning Programme Grundtvig [LLPG], 2012). The rationale for encouraging planning is the understand- 
ing that many people in mid-life are underprepared for and vulnerable to the challenges that later life can bring (e.g., European Commission, 2018; Financial Conduct Authority [FCA], 2017). Yet mid-life is seen as a pivotal life stage, during which change can have a positive impact on future trajectories (e.g., Hagger-Johnson et al., 2017; Lachman, 2015; LLPG, 2012). This focus on encouraging individuals to engage in greater levels of planning has also been accompanied by steps to oblige people to work longer and save more. For example, along with many other high-income countries, the UK is raising its state pension age. The first step was to raise the state pension age for women from 60 to 65 in 2018, to match that of men, and further rises for both sexes are planned for coming years (Cridland, 2017). The UK also introduced, in 2012, a policy of auto-enrolment in employer-sponsored occupational pensions, which are a form of private pension that supplements the state pension. The scheme requires employers to put qualifying staff into an occupational pension scheme and to make contributions towards their employee's pension. Staff can choose to 'opt out' subsequently. Both these developments should be considered in the context of the rollback of the welfare state in the UK and a corresponding shift in responsibility from the state to the individual for wellbeing in later life.

A focus on planning can serve the same purpose. Planning is frequently promoted from successful and productive ageing paradigms, which can imbue it with a normative assumption about the control that individuals have over their ageing. For example, Rowe and Kahn (1998) state that their "main message is that we can have a dramatic impact on our own success or failure in aging. Far more than is usually assumed, successful aging is in our own hands" (Rowe \& Kahn, 1998, p. 18). Furthermore, "to succeed...means having desired it, planned it, worked for it" (Rowe \& Kahn, 1998, p. 37). This perspective not only frames planning as a strategy for improving wellbeing, but it places responsibility at an individual level, in a manner criticised by others (e.g., Bauman, 2002; Rose, 1999). As a result, many argue that the successful ageing paradigm fails to take full account of the socio-economic structuring of planning (e.g., Holstein \& Minkler, 2003; Katz \& Calasanti, 2014; Moffatt \& Heaven, 2017; Street \& Desai, 2011). At its worst, therefore, a policy to promote planning can carry with it a level of blame directed at the very people least able to plan in practice.

Other reviews of the literature treat the subject slightly differently from this one. Street and Desai (2011) reviews a selection of sociological literature as a means to highlight theoretical and empirical shortcomings in the field. Others review the psychological literature on retirement (Wang \& Shi, 2014) and on planning for retirement (Adams \& Rau, 2011). A systematic review of factors promoting retirement adjustment (Barbosa, Monteiro, \& Murta, 2016) considers planning as a candidate factor but does not tackle the central task of this study: to identify the structural barriers to planning. Interestingly, Barbosa et al. (2016) did not find that re- tirement preparation was among the strongest determinants of positive outcomes in retirement, which included physical health, finances and retirement voluntariness. Another feature which sets this review apart is its focus on later life rather than retirement. A focus on retirement is critiqued elsewhere for its gendered assumption that the end of paid work marks a key turning point in people's lives (Kornadt \& Rothermund, 2014). Furthermore, retirement is becoming a gradual process, marked by periods of flexible or part-time work. There is also a contrast between studies which envisage retirement as a discrete decision versus those which see it as a lifecourse transition (see Wang \& Shi, 2014).

\section{Methodology}

\subsection{Capturing Planning Empirically}

Literature on financial planning dominates the field, providing a number of reviews and large-scale quantitative studies. This reflects a productivist view of ageing (critiqued, for example, in Foster \& Walker, 2015) and, by extension, a tendency towards research on measurable phenomena. As a result, other significant forms of planning that are harder to capture get relatively little attention (Street \& Desai, 2011). These include planning that does not result in a change in activity, for example, deciding not to move into a new house, or that is harder to measure, for example planning to maintain friendships. Reactive planning resulting from unforeseen changes in circumstances, such as involuntary retirement, is also under recognised.

\subsection{Review Design}

The approach adopted in this scoping review broadly follows the methodological framework developed by Arksey and O'Malley (2005) and expanded by Levac, Colquhoun and O'Brien (2010). This article reports on analysis conducted as part of a larger review (Preston, Drydakis, Forwood, Hughes, \& Burch, 2018). The aim of this analysis was to identify structural barriers to planning, where 'structures' refer to "constructed frameworks and patterns of organisation that serve to constrain or direct human behaviour" (Bilton et al., 2002 , p. 15). This was operationalised to include socioeconomic group, occupation, education, marital status, gender, religion and ethnicity.

The review search process comprised two stages: the first was a single systematic search of databases to identify studies related to planning in the following domains: financial, paid work, emotional/psychological, social, housing, care, physical activity, leisure, health. The second comprised snowball searching in domains where relatively little literature was found.

Several databases were used to identify suitable articles: Applied Social Sciences Index and Abstracts, Science and Social Science Citation Indices, PsycINFO, 
PsycARTICLES, Psychology and Behavioural Sciences Collection, Education Resources Information Centre, Business Source Premier, Medline, Embase, Cochrane Database of Systematic Reviews, CENTRAL, Database of Reviews of Effects, Health Technology Assessment, IDEAS, and Scopus.

The search terms comprised combinations of variants on 'mid-life', 'pre-retirement', 'planning', 'preparing', 'older' and 'ageing'.

Inclusion criteria were research or review articles published in peer-reviewed journals, books and grey literature reports between 1 January 2000 and 31 April 2018, reported in any language but with an abstract in English; study participants or populations based in any high-income countries (as defined by the World Bank) applicable to the UK ageing and policy environment; a home and/or work setting; adults of any age but focusing on those at mid-life (defined as 40 to 60 years old).

Exclusion criteria were studies which focused exclusively on people with terminal illness, specific mental illness, specific health conditions or cognitive decline, and studies in a health-related or social carerelated establishment.

A best-evidence hierarchy was applied to abstracts of all studies meeting the inclusion criteria. The hierarchy favoured good, recent systematic reviews or narrative reviews, followed by recent, good quality, published primary research from the UK that addressed the issue directly. We focused on UK evidence but where there was little good UK evidence on a specific topic, we then used evidence from other countries meeting the inclusion criteria, rather than not addressing the topic. Full text articles were subsequently assessed for eligibility on the basis of their relevance in identifying structural barriers to planning for later life and their quality in respect of this task. Quality was judged by applying the appropriate Critical Appraisal Skills Programme checklist (available at casp-uk.net/casp-tools-checklists) and only studies which at least two authors agreed were of medium or strong quality were included in the final selection. Any disagreements were resolved by discussion among members of the research team. This resulted in 36 unique studies which were then subjected to narrative synthesis. The synthesis involved a process of charting, similar to that described in Arksey and O'Malley (2005). Using a spreadsheet, the material was sorted according to key features of the studies (such as methodology and participant information). Extracts from study findings and conclusions which addressed the issue of structural barriers to planning were also copied into a spreadsheet. This enabled the team to identify similarities and differences among the included studies, as well as drawing attention to gaps in the literature.

\section{Findings}

The findings are arranged according to the domain of planning. Financial literature dominated the field, as other reviews have noted (e.g., Street \& Desai, 2011). By contrast, there were surprisingly few studies on planning for health and an absence of eligible studies on planning for social connections, leisure activities, and emotional and psychological wellbeing. Of the included studies, $75 \%$ were of UK origin but the review also included studies originating in US, Canada, Japan, Australia and various European countries.

\subsection{Planning in General}

Various studies which looked at planning across domains identified socio-demographic characteristics of people who were more or less likely to have engaged in planning. A higher income, being from managerial and professional occupation, having higher educational qualifications and being aged 50 to 64 were associated with an increased likelihood of people saying they had "hopes and ambitions" for later life, as opposed to saying that they had not thought about it much or at all, in Humphrey, Lee and Green (2011). Men were found to be more likely to have engaged in any planning and to have engaged earlier than women in Moen, Sweet and Swisher (2005). Gender and income were also found to affect likelihood of planning in a qualitative study (Denton et al., 2004). It found that low income women, who were divorced or separated, accounted for the majority of people it identified as living "day-by-day", meaning they were more likely to plan reactively than proactively (Denton et al., 2004). The study concluded that gender, work history, and marital status combined to influence people's ability to plan in general and it suggested that socio-economic constraints make financial preparation, in particular, an "unaffordable luxury" for disadvantaged groups (Denton et al., 2004, p. 80). The notion of capability to plan was developed in a study looking at wellbeing through retirement transitions (Heaven et al., 2016). Drawing on the work of Amartya Sen (1985), the authors characterised affordability as the capability to meet particular objectives by having enough money to purchase services and goods. Although the study considered affordability to be an essential component of capability, it concluded that the capability to mobilise various resources to achieve particular goals and respond to changing circumstances was key to wellbeing through retirement transitions.

As to the conception of social actors in the literature on planning, this review found that most literature on planning uses individuals as its unit of analysis. There is some recognition that spouses and partners serve as important frames of reference: for example, a review of literature about factors that affect people's ability to extend their working life (Nilsson, 2016) cites various studies demonstrating that spouses and partners served as important frames of reference in planning decisions. Meanwhile primary research has shown that partners in dual-earner couples often perceive their two retirements as "tied" transitions (Moen et al., 2005), that women often retire from work to complement their husband's 


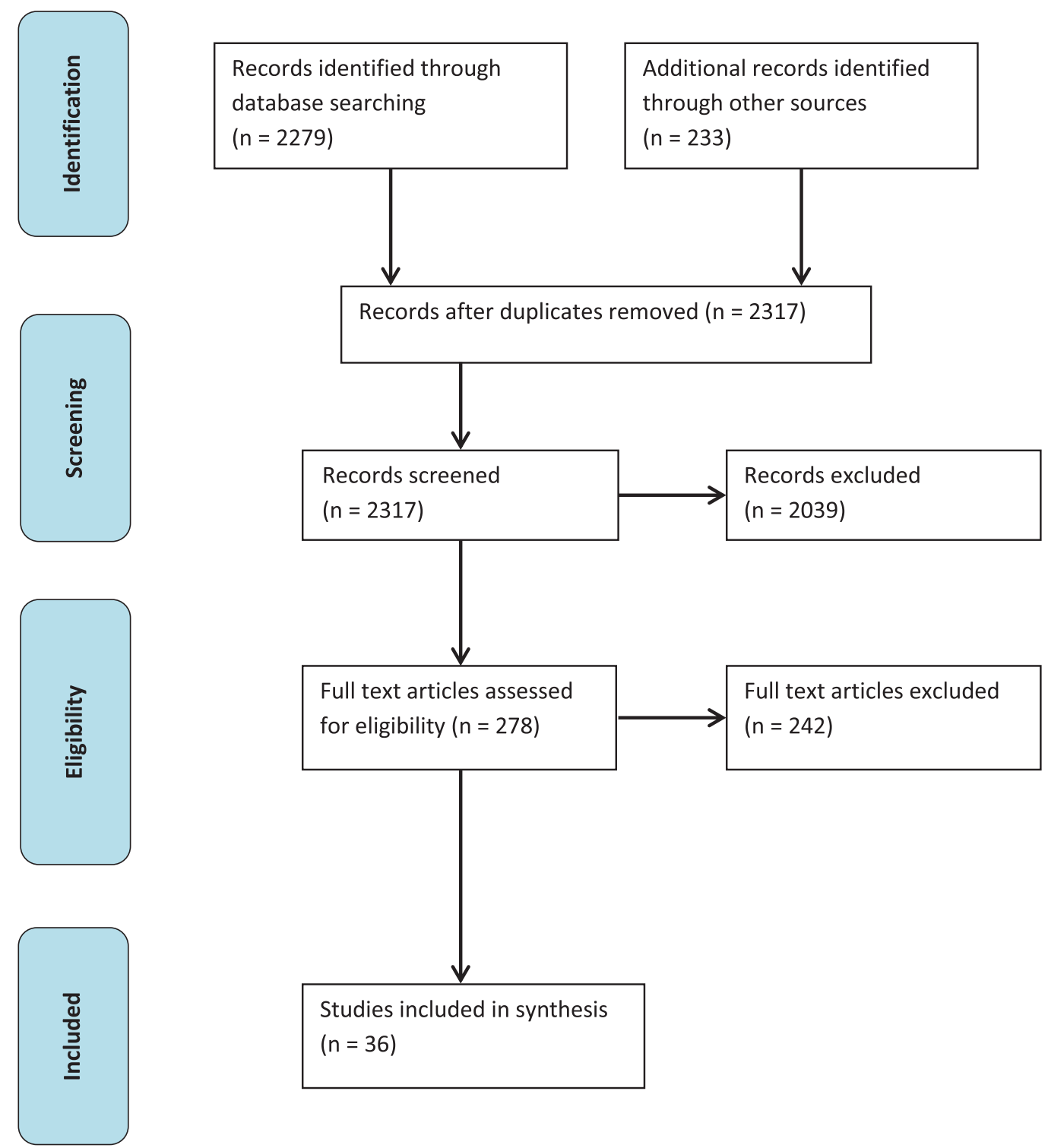

Figure 1. PRISMA flow diagram.

plans for retirement (Loretto \& Vickerstaff, 2015) and that there is a tied aspect to couples' financial decision making (Heraty \& McCarthy, 2015; Lloyd \& Lord, 2015). However, a review of literature on retirement saving makes the point that social influences have been overlooked in many studies in that field (Gough \& Niza, 2011).

\subsection{Financial Planning}

Two literature reviews identified financial resources as central among the determinants of financial planning and saving for retirement (Gough \& Niza, 2011; Personal Finance Research Centre [PFRC], 2016). They also found that policy change and other uncertainties in the financial environment were likely contributors to people's reluctance to engage in financial planning (Gough \& Niza, 2011; PFRC, 2016).

The PFRC (2016) study comprised a review of literature on financial capability. It defined financially capable behaviours as managing money well day-to-day; managing and preparing for life events; and dealing with financial difficulty. The model of financial capability it used linked these behaviours to financial wellbeing (current wellbeing and longer-term financial security). It found that analysis of large-scale survey data supported the idea that people who manage money well day-to-day are better placed to plan for retirement and that, to a large extent, this is facilitated or limited by people's financial situation and the financial resources available to them. A review of international literature on retirement saving found that salary, age, education and job tenure were key determinants of the decision to save via retirement plans (Gough \& Niza, 2011). The review noted that older, white and more educated people tended to earn more, and higher job tenure was also associated with higher wages. Studies it reviewed also showed that older workers and high earners tended to contribute to the maximum plan or legal limit, whereas younger and lower- 
income employees tended to contribute at the employermatched level (this finding refers to the UK pension system, which combines a state pension with various forms of private pension, including employer-sponsored occupational pensions). The review found relatively little literature on the socio-demographic characteristics that influenced engagement in voluntary individual savings accounts. However, it cited one study that showed participants in these plans tended to be male, high earners, older, full-time workers and people from either white or non-black minorities.

Other studies based on primary research and secondary analysis of datasets provide further evidence in line with the findings of the reviews. One found that the challenges of living on a low income inhibited people from saving for retirement (Hall \& Keohane, 2016). Moffatt and Heaven (2017) found that the notion of financial planning for retirement was embedded as a norm among participants but that the possibilities of doing so were structured by occupational social class and gender.

Heraty and McCarthy (2015) found that people employed on temporary contracts tended to have lower incomes and were therefore less likely to plan financially for retirement than those who were employed on a permanent basis. Low income was also identified as a barrier in regard to people in defined contribution pensions: low-income retirees demonstrated a reduced ability to save, compared to pre-retirees and retirees (Lloyd \& Lord, 2015). Finney and Hayes (2015) looked at financial planning through the lens of financial capability. Planning ahead was seen as one of six dimensions of financial capability, the others being: making ends meet, organised money management, controlled spending, staying informed and choosing products. Planning ahead was defined as the extent to which someone makes provision for future expenditure from current income. The study offered strong evidence that people living in lower income households lacked planning capability compared to high earners. It also found that unemployed people lacked planning capability and suggested this was likely a reflection of their low incomes relative to employed people.

These findings are corroborated by studies investigating pensions saving in particular. Two of these investigated eligible non-savers, defined as those employees eligible for a workplace pension with employer contributions but who do not participate (Bryan \& Lloyd, 2014; Bryan, Lloyd, Rabe, \& Taylor, 2011). Bryan and Lloyd (2014) found that eligible non-savers were less educationally qualified than savers, earned less, and were more likely to rent rather than own their home. The study also found that they were disproportionately male, younger, single, and had fewer children than occupational pension savers. Eligible non-savers were also less likely to save into non-pension products, have lower levels of liquid savings, have more liquid debt and were more likely to be in arrears with household bills. Bryan et al. (2011) found that mortgage holders or tenants were less likely than outright home owners to save to a pension. It also found that the great majority of eligible non-savers, compared to occupational pension savers, were in the private sector, worked in smaller establishments, were disproportionately likely to work in retail and catering, and were more likely to be part-time employees (Bryan et al., 2011). However, it found that while exit rates from a pension were higher in the private sector, they did not appear to be higher in smaller establishments or in the retail sector.

Clark, Knox-Hayes and Strauss (2009) found that the younger the individual, the lower their income, and the lower the degree to which they recognised that pensions are designed to supplement retirement income, the less likely they were to believe pension planning to be important, to be prepared for planning, and to be knowledgeable about annuities. Moreover, women were less likely than men to believe pension planning to be important.

Two studies provide evidence on the relationship between financial planning and ethnicity. Vlachantoni, Feng, Evandrou and Falkingham (2017) examined the factors associated with the receipt of three different kinds of pension income among older men and women from separate Black and Minority Ethnic (BME) groups. The three kinds of pension were: State Pension, occupational/private and Pension Credit (a means tested topup benefit). Of these, receipt of occupational/private income is the closest proxy for financial planning. The study found that belonging to certain BME groups reduced individuals' chances of receiving the State Pension or an occupational/private pension but increased their chance of receiving Pension Credit. The gender-specific analysis showed that these results held true for many BME groups of men, whereas among women, only Pakistani women were less likely than White British women to receive an occupational/private pension. An earlier study on savings behaviour of ethnic minorities in the UK found that income rather than ethnicity appeared to be the prime driver of savings levels (Gough \& Adami, 2013).

Having caring responsibilities was found to affect saving in Ipsos Mori (2013). It found that $63 \%$ of dual carers (people who care for older and younger relatives/friends) reported that they had cut their savings rate and $25 \%$ their pension contributions and retirement plans since becoming carers.

Meanwhile, the association between sexual-orientation, occupational class and likelihood of financial planning was investigated in Guasp (2011). It found that lesbian, gay and bisexual (LGB) people were more likely than their heterosexual peers to have plans in place for their future financial needs but, in both categories, a higher occupational class was associated with more financial planning.

\subsection{Will Making}

Financial resources, age and marital status were found to be independently associated with the likelihood of hav- 
ing made a will in Humphrey et al. (2011). The study found that $9 \%$ of those with assets worth up to $£ 10,000$ had made a will, compared to $80 \%$ of those with assets valued at more than $£ 500,000$. Those who had themselves received something on another's death were more likely to have made a will than those who had not (Humphrey et al., 2011).

\subsection{Health and Care}

This review found just one study (Humphrey et al., 2011) that quantified planning at mid-life with a view to improving later-life health, rather than current health. More often, literature measuring adoption of healthy behaviours is oriented to current benefits of that behaviour. This perhaps reflects the understanding from the behaviour change literature that a present benefit is likely to be a more effective incentive to adopt behaviour than a future one (Bashir, Wilson, Lockwood, Chasteen, \& Alisat, 2014). Humphrey et al. (2011) asked respondents which, if any, from a list of possible activities they were doing to maintain their long-term health. Among all age groups (16 and over), respondents who said they did nothing to maintain their long-term health tended to be of lower socio-economic status.

The review also found evidence that a structurallyrelated fatalistic attitude about health was a barrier to planning for the future. In a qualitative study looking at health and retirement, various participants expressed the feeling that there was little point planning for later life because they did not know how long they would live (Brown \& Vickerstaff, 2011). The report describes such pessimism about morbidity and mortality as a form of bounded rationality, related to the disadvantaged circumstances that the people who expressed it were facing. Similarly, mid-life, female caregivers cited that a lack of resources, coupled with the unpredictable nature of health and illness were inhibiting them from planning for later life (Pope, 2012).

In regard to planning for care in later life, this review excluded the majority of literature identified because it focused on older rather than mid-age people. This reflects the finding that the closer people are to a particular stage of later of later life, the more likely they are to plan for it (Kornadt \& Rothermund, 2014). For example, the likelihood of making a living will was found to increase with age (Moorman \& Inoue, 2012) but also with higher education and marital status (Carr \& Khodyakov, 2007). Separately, there was a suggestion that perceived inadequacy in health and social care services hinders planning for some sections of the population. One study showed $61 \%$ of LGB people said they were not confident that social care and support services, such as paid carers, would be able to understand and meet their needs; whereas $51 \%$ of heterosexual people felt the same way (Guasp, 2011). Similar concern about inadequate diversity of care homes was evident in a study of ethnic minority populations (Khan, 2012).

\subsection{Retirement from Paid Work}

The literature shows that the timing of retirement is often not a matter of choice for the retiree, presenting a major barrier to proactive planning for those affected. Involuntary retirement was associated with low incomes in Matthews and Nazroo (2016) and DWP (2016). For example, the DWP research found that just under a half of those in the highest income quartile retired because they wanted to, compared with just under a third of those in the lowest income quartile (DWP, 2016). People on low incomes were also found to be uncertain about their ability to realise plans to work beyond retirement age (ILC-UK \& UF Research Consortium, 2017).

A number of studies identified affordability as a major determinant of retirement timing (Hofäcker, Schroeder, Li, \& Flynn, 2016; ILC-UK \& UF Research Consortium, 2017; Matthews \& Nazroo, 2016). Furthermore, one review showed that affordability varied by employment sector (ILC-UK \& UF Research Consortium, 2017) and another that lower education and skill level were associated with involuntary retirement (Hofäcker et al., 2016). The former also demonstrated that choice in retirement is gendered, finding that for many women, the need and ability to work longer was shaped by their work histories and family circumstances. By contrast, Hofäcker et al. (2016) found little difference in the incidence of involuntary retirement by gender, but it did find that men are more likely to exit via employer provided preretirement schemes, while women frequently retired for personal reasons. A similar point is made in a study that found women were more likely to take a domesticallydriven pathway into retirement, mainly in response to issues of caring (Loretto \& Vickerstaff, 2015). The study also evidenced differences in discourses about retirement among men and women. It found that a discourse of 'choice and control' was mainly articulated by men, while a discourse of 'fitting in', or shaping retirement expectations around others' needs, was almost exclusively expressed by women (Loretto \& Vickerstaff, 2015). In addition, it found that women were less prone to ask about flexible working in case it upset their employer and were more likely to retire in order not to be a nuisance. The impact of informal caring, which is predominantly carried out by women, on subsequent unemployment was investigated in King and Pickard (2013). It found that caring for more than 10 hours per week significantly increased the likelihood of unemployment two years later among people in mid-life (King \& Pickard, 2013).

There is also evidence that, in the UK, a lack of support from employers is hindering planning about retirement timing, despite national policy putting the onus on employers to recruit and retain older workers (ILC-UK \& UF Research Consortium, 2017). The study suggested, for example, that age discrimination legislation was unintentionally making line managers worried about talking to people about their retirement plans for fear of being accused of ageism. Another study echoes this finding, sug- 
gesting that employers were wary of conducting analyses of the age structure of their workforce for fear of contravening equal opportunities legislation (DWP, 2017). Organisations surveyed typically did not have processes in place for discussing retirement plans with older workers. Plans for retirement were discussed informally, if at all, and discussions were usually initiated by the older worker (DWP, 2017).

\subsection{Housing}

As with retirement, the literature on housing evidences structural barriers affecting the degree of choice people have regarding housing in later life and hence their ability to plan. Early post-retirement 'lifestyle migration' was found to be concentrated in more well-off households in Pennington (2013), which also found that those who moved to a new house in later life tended to be in a high or low income bracket, while those who stayed in the same home were in a middle income bracket. A suggestion of involuntary relocation was also evident in the finding that older people who rented their home were more likely to move to a new house than homeowners, who in the UK tend to have higher incomes (Hillcoat-Nalletamby \& Ogg, 2014; Pennington, 2013).

Several UK studies also demonstrated that a lack of suitable housing discourages older people from planning to move house (Communities and Local Government Committee [CLGC], 2017; Pannell, Aldridge, \& Kenway, 2012; Pennington, 2013) and that private renters face additional barriers to planning, particularly a lack of support from landlords in adapting housing for ageing (CLGC, 2017; Pannell et al., 2012).

\section{Conclusion}

This review builds on an earlier overview of sociological literature (Street \& Desai, 2011) by providing evidence from quantitative and qualitative research of the socioeconomic structuring of individuals' ability to plan at midlife for their later life. Chief among factors that inhibit planning is low income. This is shown to hinder planning across various domains and activities. However, the impact of low income is accentuated by its co-occurrence with other factors, such as occupational and marital status, low education, few assets, living in rental accommodation, part-time work and informal caring. In combination, these factors result in people having little control over the trajectory of their lives. Not only is it evident that these barriers are intersectional but also that disadvantage regarding planning accumulates over the life-course. As a result, one of the groups least likely to engage in later life planning are divorced or separated, low-income women. This example also illuminates the gendered nature of planning. Planning is defined as deliberate and future-oriented but attempts to record it mean that concrete planning activities such as pension contributions prevail over less measurable activities such as keeping up friendships. Because women tend to have more disrupted work histories and lower pay than men, they may therefore register as poorer planners. Two main conclusions can be drawn: firstly, insofar as policy places responsibility for later life on individuals, policymakers should, as a minimum, ensure that 'responsible action' at an individual level is conceived and recorded in the most inclusive manner possible; secondly, insight gained from understanding that the ability to plan is socio-economically structured can be used to better target support as people age. The review also provides useful evidence in this regard, demonstrating that lack of support from employers and landlords hampers planning, as does inadequate housing provision and care services.

The changing legislative and regulatory environment is also found to further inhibit planning by contributing to uncertainty over the future. While uncertainty in later life is inherent, a lack of financial and other resources renders some people less able than others to respond to it. The situation regarding lack of financial resources appears to be particularly acute in the UK, which was the focus of this review. The relatively high rate of poverty among older people in the UK is evident in a report from the OECD, which attributes it mainly to the low level of the state pension (OECD, 2017). This puts in perspective policies such as auto-enrolment, which despite evidence of its positive effect on pensions contributions (Pensions Regulator, 2018), suffers from recognised drawbacks related to eligibility, coverage and adequacy (Silcock, Pike, \& Adams, 2018). Another notable feature of auto-enrolment is that it circumvents the decision to plan, by changing the defaults, and therefore does not equate to 'planning' in the sense meant in this review.

Finally, this review lends further evidence to the claim that planning literature tends to conceive social actors in a very individualist manner (Street \& Desai, 2011). It also expands the point by noting the absence in planning literature of the idea that planning can be carried out at a group or community level, despite evidence that this occurs in relation to age-friendly cities and co-housing (e.g., Brenton, 2013; Emlet \& Moceri, 2012; Steels, 2015). Overall then, the evidence suggests that planning to improve the lives of older people should be seen not only as an individual endeavour but as one that requires coordinated action by national and local government, the private sector and civil society.

This in turn raises the question of what forms of planning and by whom are most likely to improve the wellbeing of older people. As discussed, evidence in this area is scarce but a recent systematic review (Barbosa et al., 2016) found that while retirement preparation by individuals was not among the strongest determinants of retirement adjustment (including wellbeing), physical and psychological health, and finances were. This implies that an emphasis on individual planning is perhaps misplaced. Health and wealth, it seems, make for better retirement. What is less clear is that individual, rather than governmental, planning is the best route to achieving 
this. Certainly, the structural impediments to individual planning identified in this review suggest that there is great scope for governments, employers and landlords to do more to improve older people's wellbeing. But insofar as planning at the individual level has potential, one course of action this review suggests is to encourage individuals to identify existing aspects of their life at middle age which will serve them well as they age and take steps to develop or preserve these. This might include, for example, remaining in a convenient and friendly neighbourhood. Such an approach avoids what the literature suggests is the fatalism that arises from being aware of an issue but feeling powerless to do anything about it, and instead encourages people to set achievable goals.

\section{Acknowledgments}

The authors thank two advisory groups that gave invaluable support to the larger study which formed the basis of this work: The Older People's Research Group Essex and an advisory board set up by the Centre for Ageing Better, comprising academics, government and industry specialists.

\section{Conflict of Interests}

The authors declare no conflict of interests.

\section{References}

Adams, G. A., \& Rau, B. L. (2011). Putting off tomorrow to do what you want today: Planning for retirement. American Psychologist, 66(3), 180-192.

Arksey, H., \& O’Malley, L. (2005). Scoping studies: Towards a methodological framework. International Journal of Social Research Methodology, 8, 19-32.

Barbosa, L. M., Monteiro, B., \& Murta, S. G. (2016). Retirement adjustment predictors: A systematic review. Work, Aging and Retirement, 2(2), 262-280.

Bashir, N. Y., Wilson, A. E., Lockwood, P., Chasteen, A. L., \& Alisat, S. (2014). The time for action is now: Subjective temporal proximity enhances pursuit of remotefuture goals. Social Cognition, 32(1), 83-93.

Bauman, Z. (2002). Foreword: Individually, together. In U. Beck \& E. Beck-Gernsheim (Eds.), Individualization (pp. xiv-xix). London: Sage.

Bilton, T., Bonnett, K., Jones, P., Skinner, D., Stanworth, M., \& Webster, A. (2002). Introductory sociology. Basingstoke: Palgrave Macmillan.

Brenton, M. (2013). Senior cohousing communities: An alternative approach for the UK? York: Joseph Rowntree Foundation.

Brown, P., \& Vickerstaff, S. (2011). Health subjectivities and labor market participation: Pessimism and older workers' attitudes and narratives around retirement in the United Kingdom. Research on Aging, 33(5), 529-550.

Bryan, M., \& Lloyd, J. (2014). Who saves for retirement?
2: Eligible non-savers. London: Institute for Social and Economic Research.

Bryan, M., Lloyd, J., Rabe, B., \& Taylor, M. (2011). Who saves for retirement? London: Institute for Social and Economic Research.

Carr, D., \& Khodyakov, D. (2007). End-of-life health care planning among young-old adults: An assessment of psychosocial influences. Journals of Gerontology Series B: Psychological Sciences and Social Sciences, 62(2), S135-S141.

Chartered Institute of Personnel and Development. (2016). Creating longer, more fulfilling working lives: Employer practice in five European countries. London: CIPD.

Clark, G. L., Knox-Hayes, J., \& Strauss, K. (2009). Financial sophistication, salience, and the scale of deliberation in UK retirement planning. Environment and Planning A, 41(10), 2496-2515.

Communities and Local Government Committee. (2017). Housing for older people: Second report of session 2017-19. London: House of Commons.

Cridland, J. (2017). Independent review of the state pension age: Smoothing the transition. Gov.uk. Retrieved from https://assets.publishing.service.gov.uk/ government/uploads/system/uploads/attachment_ data/file/611460/independent-review-of-the-statepension-age-smoothing-the-transition.pdf

Denton, M. A., Kemp, C. L., French, S., Gafni, A., Joshi, A., Rosenthal, C. J., \& Davies, S. (2004). Reflexive planning for later life. Canadian Journal on Aging/La Revue Canadienne Du Vieillissement, 23(5), S71-S82.

Department for Work and Pensions. (2013). Framework for the analysis of future pension incomes. London: DWP.

Department for Work and Pensions. (2016). Attitudes to working in later life: British social attitudes 2015. London: DWP.

Department for Work and Pensions. (2017). Employer experiences of recruiting, retaining and retraining older workers. London: DWP.

Emlet, C. A., \& Moceri, J. T. (2012). The importance of social connectedness in building age-friendly communities. Journal of Aging Research, 2012. http://dx.doi. org/10.1155/2012/173247

Eurofound. (2007). Early and phased retirement in European companies: Establishment survey on working time 2004-2005. Luxembourg: Publications Office of the European Union.

Eurofound. (2016). Changing places: Mid-career review and internal mobility. Luxembourg: Publications Office of the European Union.

European Commission. (2018). Pension adequacy report 2018: Current and future income adequacy in old age in the EU. Europa. Retrieved from https:// ec.europa.eu/social/main.jsp?catld=738\&langld=en \&publd $=8084 \&$ furtherPubs=yes

Financial Conduct Authority. (2017). Understanding the financial lives of UK adults: Findings from the FCA's 
Financial Lives Survey 2017. London: FCA.

Finney, A., \& Hayes, D. (2015). Financial capability in Great Britain 2010 to 2012. London: Office for National Statistics. Retrieved from https://www.ons. gov.uk/peoplepopulationandcommunity/personal andhouseholdfinances/incomeandwealth/articles/ financialcapabilityingreatbritain/2015-06-24

Foster, L., \& Walker, A. (2015). Active and successful aging: A European policy perspective. The Gerontologist, 55(1), 83-90.

Gough, O., \& Adami, R. (2013). Saving for retirement: A review of ethnic minorities in the UK. Social Policy and Society, 12(1), 147-161.

Gough, O., \& Niza, C. (2011). Retirement saving choices: Review of the literature and policy implications. Journal of Population Ageing, 4(1/2), 97-117.

Guasp, A. (2011). Lesbian, gay \& bisexual people in later life. London: Stonewall.

Hagger-Johnson, G., Carr, E., Murray, E., Stansfeld, S., Shelton, N., Stafford, M., \& Head, J. (2017). Association between midlife health behaviours and transitions out of employment from midlife to early old age: Whitehall II cohort study. BMC Public Health, 17(1). https://doi.org/10.1186/s12889-016-3970-4

Hall, S., \& Keohane, N. (2016). Preparing for later life; working longer and saving more. York: Joseph Rowntree Foundation.

Heaven, B., O'Brien, N., Evans, E. H., White, M., Meyer, T. D., Mathers, J. C., \& Moffatt, S. (2016). Mobilizing resources for well-being: Implications for developing interventions in the retirement transition. The Gerontologist, 56(4), 615-629.

Heraty, N., \& McCarthy, J. (2015). Unearthing psychological predictors of financial planning for retirement among late career older workers: Do self-perceptions of aging matter? Work, Aging and Retirement, 1(3), 274-283.

Hillcoat-Nalletamby, S., \& Ogg, J. I. M. (2014). Moving beyond 'ageing in place': Older people's dislikes about their home and neighbourhood environments as a motive for wishing to move. Ageing \& Society, 34(10), 1771-1796.

Hofäcker, D., Schroeder, H., Li, Y., \& Flynn, M. (2016). Trends and determinants of work-retirement transitions under changing institutional conditions: Germany, England and Japan compared. Journal of Social Policy, 45(1), 39-64.

Holstein, M. B., \& Minkler, M. (2003). Self, society, and the "new gerontology". The Gerontologist, 43(6), 787-796.

Humphrey, A., Lee, L., \& Green, R. (2011). Aspirations for later life. London: Department for Work and Pensions.

ILC-UK, \& UF Research Consortium. (2017). Exploring retirement transitions. London: ILC-UK.

Ipsos Mori. (2013). The sandwich generation: An explanation of the affective and financial impact of dual caring. London: Money Advice Service.
Katz, S., \& Calasanti, T. (2014). Critical perspectives on successful aging: Does it "appeal more than it illuminates"? The Gerontologist, 55(1), 26-33.

Khan, O. (2012). A sense of place: Retirement decisions among older Black and minority ethnic people. London: Runnymede Trust.

King, D., \& Pickard, L. (2013). When is a carer's employment at risk? Longitudinal analysis of unpaid care and employment in midlife in England. Health \& Social Care in the Community, 21(3), 303-314.

Kornadt, A. E., \& Rothermund, K. (2014). Preparation for old age in different life domains: Dimensions and age differences. International Journal of Behavioral Development, 38(3), 228-238.

Lachman, M. E. (2015). Mind the gap in the middle: A call to study midlife. Research in Human Development, 12(3/4), 327-334.

Levac, D., Colquhoun, H., \& O’Brien, K. K. (2010). Scoping studies: Advancing the methodology. Implementation Science, 5, 1-9.

Lifelong Learning Programme Grundtvig. (2012). Pre-retirement counselling: A shortcut to active ageing. Brussels: European Commission. Retrieved from https://www.researchgate.net/publication/ 260962635_Active_Ageing_and_Pre-retirement_ counseling_The_final_report_from_a_Partnership_ under_the_EU_LLP_Grundtvig_Programme

Lloyd, J., \& Lord, C. (2015). Defined capability: Pensions, financial capability and decision making among retirees. London: Strategic Society Centre.

Loretto, W., \& Vickerstaff, S. (2015). Gender, age and flexible working in later life. Work, Employment and Society, 29(2), 233-249.

Matthews, K., \& Nazroo, J. (2016) Retirement, well-being, engagement and social status. In J. Banks, G. D. Batty, J. Nazroo, \& A. Steptoe (Eds.), The dynamics of ageing: Evidence from the English longitudinal study of ageing 2002-15 (Wave 7) (pp. 57-100). London: Institute for Fiscal Studies.

Moen, P., Sweet, S., \& Swisher, R. (2005). Embedded career clocks: The case of retirement planning. Advances in Life Course Research, 9, 237-265.

Moffatt, S., \& Heaven, B. (2017). 'Planning for uncertainty': Narratives on retirement transition experiences. Ageing \& Society, 37(5), 879-898.

Moorman, S. M., \& Inoue, M. (2012). Persistent problems in end-of-life planning among young-and middle-aged American couples. Journals of Gerontology Series B: Psychological Sciences and Social Sciences, 68(1), 97-106.

Nilsson, K. (2016). Conceptualisation of ageing in relation to factors of importance for extending working life: A review. Scandinavian Journal of Public Health, 44(5), 490-505.

OECD. (2017). Pensions at a glance 2017. Paris: OECD.

Pannell, J., Aldridge, H., \& Kenway, P. (2012). Market assessment of housing options for older people. London: Shelter \& Joseph Rowntree Foundation, New 
Policy Institute.

Pennington. (2013). Moving on: Migration trends in later life. London: IPPR.

Pensions Regulator. (2018). Automatic enrolment: Commentary and analysis, April 2017-March 2018. Darlington: Pensions Regulator.

Personal Finance Research Centre. (2016). Financial capability and retirement. London: Money Advice Service.

Pope, N. D. (2012). Female caregivers' plans for late life. Qualitative Social Work, 12(4), 507-522.

Preston, C., Drydakis, N., Forwood, S., Hughes, S., \& Burch, S. (2018). Planning and preparing for later life. London: Centre for Ageing Better.

Rose, N. (1999). Powers of freedom: Reframing political thought. Cambridge: Cambridge University Press.

Rowe, J. W., \& Kahn, R. L. (1998). Successful aging. New
York, NY: Random House.

Sen, A. (1985). Commodities and capabilities. Amsterdam: Elsevier Science Publishers.

Silcock, D., Pike, T., \& Adams, J. (2018). How would removal of the State Pension triple lock affect adequacy? London: Pensions Policy Institute.

Steels, S. (2015). Key characteristics of age-friendly cities and communities: A review. Cities, 47, 45-52.

Street, D., \& Desai, S. (2011). Planning for old age. In R. A. Settersten \& J. L. Angel (Eds.), Handbook of sociology of aging (pp. 379-397). New York, NY: Springer.

Vlachantoni, A., Feng, Z., Evandrou, M., \& Falkingham, J. (2017). Ethnic elders and pension protection in the United Kingdom. Ageing \& Society, 37(5), 1025-1049.

Wang, M., \& Shi, J. (2014). Psychological research on retirement. Annual Review of Psychology, 65, 209-233.

\section{About the Authors}
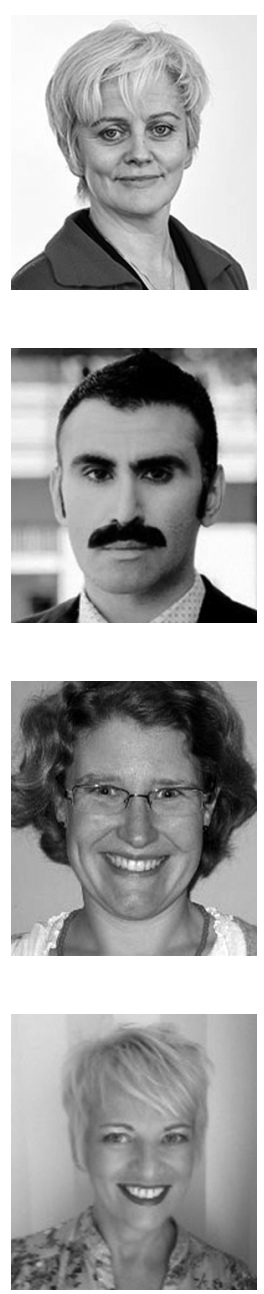

Suzanne Hughes (Dr), following her Social Work Masters, was keen to use her research skills to explore older people's experiences of domiciliary care, paying particular attention to identity, autonomy and relationship. This she did through an Anglia Ruskin funded PhD. In her Doctoral role, Sue has contributed to a range of projects, championing through both research and education, the understanding and appreciation of service-user and patient experiences of health and social care situations.

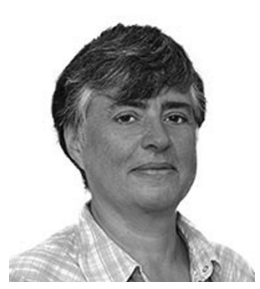

Catherine Meads is a senior systematic reviewer, and has published numerous evidence syntheses, systematic reviews and health technology assessments, including music for recuperation after surgery, therapeutic writing in long-term conditions, and in sexual orientation and health. Previously, Catherine was Research Leader at RAND Europe in Cambridge, Reader in Health Technology Assessment at Brunel University, Senior Lecturer at Bart's and The London School of Medicine and Dentistry and University of Birmingham. 